\title{
Effectiveness of gratitude on psychological well-being and quality of life among hospitalized substance abuse patients
}

\author{
Maryam Jamshidian Ghalesefidi', Jahangir Maghsoudi ${ }^{1}$, Behrooz Pouragha ${ }^{2}$
}

\begin{abstract}
Background: Substance abuse is a chronic phenomenon that affects many physical, psychological, social, familial and economic elements. Objective: This study was conducted in order to investigate the effectiveness of gratitude on individual's well-being as well as the quality of life (QoL) of hospitalized substance abuse patients.

Methods: The current study was clinical trial study. The research was conducted on 64 addicted patient which had been referred to the addiction rehabilitation center (Modarres hospital) of Isfahan city, that divided to two groups that each one included 32 patients.GQ-6, WHOQOL, and WHO-6 questionnaires used for estimate of gratitude, QoL, and well-being scores respectively. The SPSS 16 software was used for analyzing the collected data. Results: There is a relationship between gratitude, well-being, and QoL after the intervention in two groups of the study while there is no any significant difference between these variables before the intervention. Also, there were significant correlation between the gratitude, QoL, and well-being pre and post follow up of patients.

Conclusion: It seems that gratitude improves and increased of QoL and psychological well-being during addiction treatment program.
\end{abstract}

Keywords: gratitude, well-being, quality of life, addiction, WHOQOL-BREF, SF-26 scale, GQ-6

\section{INTRODUCTION}

Most writings on ethics and different religions discuss gratitude as a moral obligation that involves feelings and expressions of appreciation in response to received benefits. Lazarus and Lazarus defined gratitude as an "empathic emotion" that is characterized by feelings of appreciation in response to benefit or gift (1).

Gratitude as a dispositional trait has been consistently shown to be associated with subjective well-being affect (2). McCulliugh et al. (3) reported that gratitude had positive correlation with the level of life satisfaction, positive affect, optimism, hopefulness, as well as vitality. In contrast, gratitude was found to have negative association with anxiety, depression, and negative affect. In addition to subjective well-being and positive affect, gratitude is correlated with prosocial traits and behaviors such as empathic concern and perspective taking (2).

Drugs abuse is one of the important and serious problems at the international level that can affect various aspects of economic, social, physiological and psychological wellbeing. Statistics show that about $16 \%$ of Iranian addicts are under the age of 19, and about $28 \%$ begin using drugs between the ages of 20 and 24 (4). According to United Nations Population statistics, the number of drug users between 15 and 24-year-old worldwide is 200 billion individuals, or in other words they compromise of $5 \%$ of the total world's population. Among them, 16 billion individuals, $4 \%$ of the world's population), use opiates. At least half of those receiving treatment relapse within six months, and the number of those who relapse within a year of treatment is $75 \%$ (5). These findings emphasize the importance of preventing and identifying risk factors and protection methods.

Several studies have been done with opioid abusers and has been shown association with poorer QoL. Use of gratitude programs may be improve QoL and well-being in drug abusers (6).

\footnotetext{
1 Department of Psychiatric Nursing, Faculty of Nursing and Midwifery, Isfahan University of Medical Sciences, Isfahan, Iran.

2 Department of Public Health, Alborz University of Medical Sciences, Karaj, Iran.
}

Correspondence: Jahanghir Maghsoudi

Department of Psychiatric Nursing, Faculty of Nursing and Midwifery, Isfahan University of Medical Sciences, Isfahan, Iran

Received: 26 Apr 2018, Accepted: 1 Jul 2018

(c) 2019 by the authors; licensee Modestum Ltd., UK. This article is an open access article distributed under the terms and conditions of the Creative Commons Attribution License (http://creativecommons.org/licenses/by/4.0/). 


\section{OBJECTIVE}

Given the importance of the role of gratitude on well-being and QoL people especial addicted patients, the purpose of this study is to compare the gratitude, well-being as well as QoL in hospitalized addicted patients in Isfahan.

\section{METHODS}

\section{Participants}

This study is clinical trial research that is done between January 2016 and July 2017. Sampling method is accessible. The sample of this study was recruited from the Modarres hospital as a rehabilitation center for addicted patients in Isfahan and it's related to Isfahan University of Medical Sciences. It was estimated that the samples size was equal to 64 participants, considering a confidence interval of $95 \%$, and statistically power of $80 \%$. Also, it was assumed that the correlation coefficient between the respective variables is $r=0.7$, in order to consider the relationship among the variables significant statistically. The sample consisted of 32 drug addicted as a test group ( 22 men and 10 women) and 32 addicted individuals as a control group ( 28 men and 4 women). The researcher supervised and attended the aforementioned center in person during the week, and distributed the questionnaires among participants, flowing from introducing themselves and stating the research objective, providing and expanding the required explanations in regards to how to fill the questionnaires, finally gathered written consent forms from participants. All questionnaires are completed and obtained at the first day of selection of two groups. However, the other questionnaire are completed and obtained at the fourth days after the gratitude program for each groups.

\section{Inclusion Criteria}

These criteria were ability to read and write, no clinical diagnosis of schizophrenia or any other psychological disorder, no received a recent psychology treatment support such as behavioral or recognition therapy and finally the participant must have not any disability.

\section{Exclusion Criteria}

Participants that have three absences during the research, psychological crisis such as high stresses between the study and unwillingness to help and participates in the study are excluded of the study.

\section{Ethics}

The presented study was conducted in accordance with Helsinki declaration (1974) and was approved by the Research Ethics Committee of Isfahan University of Medical Sciences. Informed consent was obtained from all the participants.

\section{Tools \\ Gratitude}

The gratitude level was scaled and measured with the use of Gratitude Questionnaire (GQ-6) (3), established by Kossakowska and Kwiatek (7). The gratitude questionnaire contains six items which are assessed on a 7-point Likert scale, where 1 stands for "strongly disagree," and 7-"strongly agree." The measure is homogeneous: it contains 1 factor, which is entitled "gratitude" (7). Four entries refer to gratitude, and two to difficulty with expressions or sensation gratitude, essential to be recoded at the calculation of results. The level of gratitude is attained by taking into account all the entries. The possible scores range from 7 to 42 . The reliability of the GQ- 6 scale analyzed with Cronbach's a coefficient which was 0.83 .

\section{QoL}

The WHOQOL-BREF is a global cross-culturally comparable QoL evaluation tool. It is available for both developed and developing countries in different languages (8), and it is a general QoL apparatus developed by WHO, which is comprised of 26 items. The response or reflection selections range from 1 (very dissatisfied/very poor) to 5 (very satisfied/very good). It highlights the subjective reflections rather than the objective life circumstances, with evaluations made over four weeks. The questionnaire embraces four areas: physical as well as psychological health, social status, and environment. A linear scale between 0 and 100 was used to transform and display scores, with 0 being nominated as for the slightest favorable and 100 being assigned for the most favorable. The individual obtains a score between 0 and 100 in each aspect; the scores closer to 100 indicate better QoL. Trustworthiness and validity of the Persian interpretation of 
this survey were confirmed in the study by Montazeri et al. (9). Customary reliability factors alternated from 0.77 to 0.99 . In aspect of validity, the merging of variations alternated between 0.58 and 0.95 (9). In the current study, reliability of the previous questionnaire was assessed by Cronbach's alpha scheme such that the examiner distributed the surveys to 32 individuals who were being examined. Once gathering of questionnaires, Cronbach's alpha coefficient was narrated to be 0.92 for the corresponding assessment tool based upon the outputs of SPSS/16 software.

\section{Well-being}

In regard to measurement of well-being, WHO-six well-being (WHO-6) has been established by Psychiatric Research Unit, World Health Organization (10) was used. It comprised 18 elements, of which divided to six indexes: self-acceptance, purposeful life, positive relationship, personality, autonomy, and environmental status. Contributors were required to evaluate entries on a 7-point scale (1-strongly disagree, 7-strongly agree). General internal coefficient for the present study was 0.9 .

\section{Statistical Analysis}

Statistical evaluation was achieved using statistical set for social sciences for windows version 18 (SPSS 18, SPSS Inc., Chicago, IL, USA). Prior to analyzing the collected statistics, all data were verified for normality and homogeneity of variation using Kolmogrov-Smirinov test. In view of the moderate sample size and the fact that many scales were not normally distributed, non-parametric tests were used thought the analysis. The $\chi^{2}$ test was applied to relate and make a comparison between the two study groups in regard to demographic records. The QoL scores, gratitude, and well-being scores were compare by $t$ dependent test in two groups. For comparison of education levels Mann-Whitney $U$ test was used in each group. Also, pre-post comparison of QoL, gratitude, and well-being scores were evaluated with paired $t$ test.

\section{RESULTS}

In this study, data from 64 addicted patients were analyzed. All patients divided to equal groups (test and control that each group included 32 patients). Table 1 was compressed of demographic variables between two groups. According to this table there was no any significant difference between the study variables.

A dependent sample $t$ test indicate that well-being, $Q o L$ and gratitude scores for test and control group had no significance difference $(p>0.05)$ before the start of study (Table 2$)$, while these scores revealed significant difference after the survey among the two sets $(p<0.05)$ (Table 3 ).

By analyzing the collected data, results showed positive significant relationship between the well-being, QoL, and gratitude with time of the study (After the intervention respect to start the study). These results were showed in Table 4. 
Table 1: Sociodemographic characters of study participants $(n=64)$

\begin{tabular}{|c|c|c|c|}
\hline Characteristic & $\begin{array}{l}\text { Test group } \\
(\mathrm{n}=32)\end{array}$ & $\begin{array}{l}\text { Control group } \\
(n=32)\end{array}$ & P-value \\
\hline Age (Mean \pm SD) (year) & $30.1 \pm 8.2$ & $30.8 \pm 12.6$ & 0.83 \\
\hline Age at the time of taking the drugs (Mean \pm SD) (year) & $20.1 \pm 3.7$ & $21.0 \pm 9.7$ & 0.66 \\
\hline Number of abandoned drugs (Mean \pm SD) & $12.8 \pm 5.3$ & $7.6 \pm 3.7$ & 0.43 \\
\hline Duration of drug use & $10.89 \pm 2.5$ & $10.88 \pm 1.9$ & 0.99 \\
\hline Number of family & $4.8 \pm 1.9$ & $4.6 \pm 1.8$ & 0.72 \\
\hline Gender & & & 0.31 \\
\hline Male & $22(68.8 \%)$ & $28(87.5 \%)$ & \\
\hline Female & $10(31.2 \%)$ & $4(12.5 \%)$ & \\
\hline Material status & & & 0.29 \\
\hline Single & $13(40.7 \%)$ & $17(53.2 \%)$ & \\
\hline Married & $15(46.9 \%)$ & $12(37.5 \%)$ & \\
\hline Divorced & $3(9.3 \%)$ & $1(3.1 \%)$ & \\
\hline Widow & $1(3.1 \%)$ & $2(6.2 \%)$ & \\
\hline Dwelling status & & & 0.47 \\
\hline Rented home & $11(34.3 \%)$ & $14(43.8 \%)$ & \\
\hline Personal home & $21(65.7 \%)$ & $18(56.2 \%)$ & \\
\hline Job status & & & 0.32 \\
\hline Unemployed & $10(31.3 \%)$ & 15 (46.9\%) & \\
\hline Employed & $4(12.5 \%)$ & $4(12.5 \%)$ & \\
\hline Retried & $1(3.1 \%)$ & $0(0 \%)$ & \\
\hline Self-worker & $13(40.7 \%)$ & $12(37.5 \%)$ & \\
\hline House keeper & $4(12.5 \%)$ & $1(3.1 \%)$ & \\
\hline The motivation to use drugs & & & 0.24 \\
\hline Fun & $10(31.3 \%)$ & $8(25 \%)$ & \\
\hline Treatment of a disease & $3(9.4 \%)$ & $3(9.4 \%)$ & \\
\hline Bad friends & $1(3.1 \%)$ & $6(18.7 \%)$ & \\
\hline Curiosity & $3(9.4 \%)$ & $2(6.2 \%)$ & \\
\hline Doping & $4(12.5 \%)$ & $3(9.4 \%)$ & \\
\hline Social problems & $2(6.2 \%)$ & $3(9.4 \%)$ & \\
\hline Other & $1(3.1 \%)$ & $0(0 \%)$ & \\
\hline Mix two or more above condition & $8(25 \%)$ & $7(21.9 \%)$ & \\
\hline Type of drugs & & & 0.18 \\
\hline Crack & $3(9.4 \%)$ & $2(6.2 \%)$ & \\
\hline Methyl amphetamine & $0(0 \%)$ & $4(12.5 \%)$ & \\
\hline Morphine & $4(12.5 \%)$ & $8(25 \%)$ & \\
\hline Opium & $2(6.2 \%)$ & $3(9.4 \%)$ & \\
\hline Hashish & $5(15.7 \%)$ & $0(0 \%)$ & \\
\hline Cannabis & $1(3.1 \%)$ & $0(0 \%)$ & \\
\hline Methadone & $3(9.4 \%)$ & $3(9.4 \%)$ & \\
\hline Use mix of above drugs & $14(43.7 \%)$ & $12(37.5 \%)$ & \\
\hline Use of alcohol & & & 0.17 \\
\hline Yes & $24(75 \%)$ & 19 (59.4\%) & \\
\hline No & $8(25 \%)$ & $13(40.6 \%)$ & \\
\hline Education level & & & 0.69 \\
\hline Elementary school & $7(21.8 \%)$ & $5(15.7 \%)$ & \\
\hline Junior school & $6(18.7 \%)$ & $8(25 \%)$ & \\
\hline High school & $5(15.7 \%)$ & $9(28.1 \%)$ & \\
\hline Diploma & $8(25 \%)$ & $4(12.5 \%)$ & \\
\hline Undergraduate & $3(9.4 \%)$ & $2(6.2 \%)$ & \\
\hline Bachelor degree & $3(9.4 \%)$ & $4(12.5 \%)$ & \\
\hline
\end{tabular}

Table 2: Comparison of the mean $\pm S D$ score of well-being, QoL and gratitude before intervention in two groups of study

\begin{tabular}{ccccc}
\hline \multirow{2}{*}{ Score } & Test group & Control group & \multicolumn{2}{c}{ Independent t test } \\
\cline { 2 - 5 } & Mean \pm SD & Mean \pm SD & t & 0.75 \\
\hline Well-being & $78.9 \pm 15.2$ & $75.9 \pm 13.6$ & 0.46 \\
\hline QoL & $57.8 \pm 14.5$ & $51.8 \pm 18.1$ & 1.22 & 0.23 \\
\hline Gratitude & $21.9 \pm 3.6$ & $20.7 \pm 4.4$ & 1.16 & 0.25 \\
\hline
\end{tabular}


Table 3: Comparison of the mean $\pm S D$ score of well-being, QoL and gratitude after intervention in two groups of study

\begin{tabular}{ccccc}
\hline \multirow{2}{*}{ Score } & Test group & Control group & \multicolumn{2}{c}{ Independent t test } \\
\cline { 2 - 5 } & Mean \pm SD & Mean \pm SD & t & P-value \\
\hline Well-being & $97.2 \pm 15.9$ & $76.3 \pm 15.5$ & 4.87 & $<0.001$ \\
\hline QoL & $78.5 \pm 10.3$ & $53.3 \pm 15.8$ & 6.90 & $<0.001$ \\
\hline Gratitude & $25.2 \pm 2.1$ & $20.8 \pm 4.9$ & 4.30 & $<0.001$ \\
\hline
\end{tabular}

Table 4: Comparison of the mean $\pm S D$ score of well-being, QoL, and gratitude of participants after intervention, compared to pre-intervention

\begin{tabular}{ccccc}
\hline \multirow{2}{*}{ Score } & Test group & Control group & \multicolumn{2}{c}{ Independent t test } \\
\cline { 2 - 5 } & Mean \pm SD & Mean \pm SD & t & P-value \\
\hline Well-being & $18.4 \pm 4.2$ & $0.4 \pm 2.86$ & 3.51 & 0.001 \\
\hline QoL & $20.7 \pm 2.8$ & $1.49 \pm 3.02$ & 4.68 & $<0.001$ \\
\hline Gratitude & $3.3 \pm 2.0$ & $0.1 \pm 0.6$ & 3.16 & 0.003 \\
\hline
\end{tabular}

\section{DISCUSSION}

Substance use disorder, for instance, concerns abuse or addiction to a substance related to increased risk of harmful consequences to the individual. In this case, the improvement of QoL becomes a rather important objective. Even though there are a few studies which has been published with their main focus concerning the QoL (5) of the drug users for initiation of the treatment, this study has primarily focused on abstinence or reduced drug related harms as for its treatment outcome.

Evaluation of QoL among the substance consumers in most the studies which has been done remain inadequate to the aspects of the health related QoL (HRQoL) (11), this is in despite the statement in which several authors have mentioned that the QoL is indeed a useful and therefore a more important concept which need to be looked on for (12). On the other hand, other authors have confirmed the negative impacts which psychotropic drugs have on the QoF on the users (13), however it is not easy to confirm whether the drug use itself contributes to negative impacts on the life of or the negative life events has induced the drug consumption. Bizzarri et al. (14) has assessed the independent effect of dual identification, gender, age and recent substance consumption on QoL of opiate-dependent patients, using the WHOQOL-BREF. In this study, a substantial impact of dual diagnosis on all four QoL aspects was verified, with a negative relationship of older age and female sex with some areas, while existing substance consumption had no significant influence on QoL. Likewise, Conroy et al. (15) did not find any association between QoL and drug-using practices among injecting drug users, but a range of psychosocial factors effected their existing QoL. Based on another study, the general QoL of substance users while they were being treated was negatively correlated with older age, certain medical conditions, severity of drug consumption, being treated in a detoxification unit and recent hospitalization for mental health status (5). Lastly, psychiatric symptoms improvement was determined to be the best predictor of better QoL amongst severely mentally ill substance users (11).

An array of mechanisms by positive emotions may contribute to wellbeing. Gratitude research has been developed based on this, overviewing at whether and to what extent these theories might account for the role of gratitude in wellbeing, including wellbeing in those experiencing clinical disorders. One of the most effective concepts in the area of positive psychology advises that positive emotions act to enhance assumed repertories and to build long-term psychological and physical effects (16). Fredrickson, who has initially established this theory, has also discovered the indirect evidence now gathering that gratitude may perform in such ways (16). Other researcher advise that positive psychological interventions are of most valuable because they are able to build pleasure, enhance engagement and sense (12). Nelson (17) recommends that gratitude may have a distinctive role in undoing certain negative emotions such as anger and stresses which are correlated with a materialistic focus. Furthermore, Seligman et al. (18) indicates that positive emotions help individuals discover positive meaning in challenging and tough circumstances, an outcome which can lead to a positive increasing spiral of emotion and can also broaden thinking, however the negative descending spiral is correlated with destructive moods and depression. Watkins et al. (19) suggested that gratitude might contribute to wellbeing by these mechanisms: 1) enhancing capability to enjoy benefits, 2) alternating emotional adaptation to statuses, including good ones, by prompting people of benefits which has been experienced, 3) distracting the person from their unpleasant emotions and negative feeling, 4) involving in an encouraging memory bias and enhancing the emphasis on the positive aspects of life, as well as 5 ) increase in social reward from other prospective. 
Following the primary theory regarding the impact of gratitude on the wellbeing, researches have started to study the specific impact of work in gratitude; for instance, a correlational study with psychotherapy outpatients $(n=72)$, Toussaint and Friedman (20), revealed that the association between gratitude and wellbeing was minimized in part mediated by positive impact.

There are several limitations to this study. Participants who addicted dependence generally have additional problems. Usually people typically seek assistance when in crisis and this may be reflected in lower QOL assessments. So, initial, focus group outcomes cannot be oversimplified and they rather reveal the individual capabilities and experiences of patients from within their own frames of reference. Moreover, the size of the sample our examined group and the number of focus groups was somewhat minor. Nevertheless, saturation of information was found at the end of the focus groups and the study was not aimed to make measureable data. Accordingly, further research will be beneficial to validate our outcomes. Thirdly, assuming the cross-sectional scheme of the study, interconnection could not be assessed. This study only takes relativities into account, since possible elements and outcomes were measured simultaneously. Upcoming longitudinal studies should state issues of directionality and linearity.

For upcoming researches, an alteration from participative to emancipatory would be worthwhile to research. In participative study, collaborative work is done by researchers and participants. Conversely, the researcher would remain as the main and leading person with main responsibilities and role in making decisions.

On the other hand, in emancipatory study, the participants build and create structure and analysis of the research; the proficiency of the researcher confirms secondary status in relation to the effort and contribution of participants themselves. By development an emancipatory methodology, drug users can be befitted as the key-decision makers in the treatment progression, which will eventually contribute to their QoL and high chance of achieving positive treatment results.

\section{REFERENCES}

1. Lazarus R, Lazarus B. Passion and Reason. Making Sense of Our Emotions. New York, Oxford University Press, 1994.

2. Breen WE, Kashdan TB, Lenser ML, Fincham FD. Gratitude and forgiveness: Convergence and divergence on selfreport and informant ratings. Pers Individ Dif. 2010;49(8):932-7. https://doi.org/10.1016/j.paid.2010.07.033 PMid:20871779 PMCid:PMC2943233

3. McCullough ME, Emmons RA, Tsang JA. The grateful disposition: a conceptual and empirical topography. J Pers Soc Psychol. 2002;82(1):112-27. https://doi.org/10.1037/0022-3514.82.1.112 PMid:11811629

4. Salmabadi M, Faroogh Sadeghbojd M, Farshad MR, Zolfaghari S. Comparing the spiritual health and quality of life in addicted and non-addicted patients in the city of Birjand, Iran. Int J High Risk Behav Addict. 2016;5(1):e23208. https://doi.org/10.5812/ijhrba.23208 PMid:27195247 PMCid:PMC4867404

5. Carpentier PJ, Krabbe PF, van Gogh MT, Knapen L, Buitelaar JK, de Jong CA. Psychiatric comorbidity reduces quality of life in chronic methadone maintained patients. Am J Addict. 2009;18(6):470-80. https://doi.org/10.3109/10550490903205652 PMid:19874168

6. Connock M, Juarez-Garcia A, Jowett S, Frew E, Liu Z, Taylor RJ, et al. Methadone and buprenorphine for the management of opioid dependence: a systematic review and economic evaluation. Health Technol Assess. 2007;11(9):1-171, iii-iv. https://doi.org/10.3310/hta11090 PMid:17313907

7. Charzynska E. Sex differences in spiritual coping, forgiveness, and gratitude before and after a basic alcohol addiction treatment program. J Relig Health. 2015;54(5):1931-49. https://doi.org/10.1007/s10943-015-0002-0 PMid:25600363 PMCid:PMC4506470

8. Zhang Y, Qu B, Lun S, Wang D, Guo Y, Liu J. Quality of life of medical students in China: a study using the WHOQOL-BREF. PloS One. 2012;7(11):e49714. https://doi.org/10.1371/journal.pone.0049714 PMid:23209595 PMCid:PMC3507917

9. Montazeri A, Goshtasebi A, Vahdaninia M, Gandek B. The short form health survey (SF-36): translation and validation study of the Iranian version. Qual Life Res. 2005;14(3):875-82. https://doi.org/10.1007/s11136-0041014-5 PMid:16022079

10. World Health Organization. Measurement of and target-setting for well-being: an initiative by the WHO regional office for europe. 2012. 
11. De Maeyer J, Vanderplasschen W, Broekaert E. Exploratory study on drug users' perspectives on quality of life: more than health-related quality of life? Soc Indic Res. 2009;90(1):107-26. https://doi.org/10.1007/s11205-0089315-7

12. Veenhoven R. The four qualities of life ordering concepts and measures of the good life. The exploration of happiness: Springer; 2013. p. 195-226.

13. Rudolf H, Watts J. Quality of life in substance abuse and dependency. Int Rev Psychiatry. 2002;14(3):190-7. https://doi.org/10.1080/09540260220144975

14. Bizzarri J, Rucci P, Vallotta A, Girelli M, Scandolari A, Zerbetto E, et al. Dual diagnosis and quality of life in patients in treatment for opioid dependence. Subst Use Misuse. 2005;40(12):1765-76. https://doi.org/10.1080/10826080500260800 PMid:16419555

15. Conroy E, Kimber J, Dolan K, Day C. An examination of the quality of life among rural and outer metropolitan injecting drug users in NSW, Australia. Addict Res Theory. 2008;16(6):607-17. https://doi.org/10.1080/16066350801911948

16. Fredrickson BL. The broaden-and-build theory of positive emotions. Philos Trans R Soc Lond B Biol Sci. 2004; 359(1449):1367-78. https://doi.org/10.1098/rstb.2004.1512 PMid:15347528 PMCid:PMC1693418

17. Nelson K, Lyubomirsky S, In: G, Friedman HS. Provided for non-commercial research and educational use. Not for reproduction, distribution or commercial use. CASRP Publishing Company Ltd., UK. 2016.

18. Seligman ME, Csikszentmihalyi M. Positive psychology. An introduction. Am Psychol. 2000;55(1):5-14. https://doi.org/10.1037/0003-066X.55.1.5

19. Watkins PC, Woodward K, Stone T, Kolts RL. Gratitude and happiness: Development of a measure of gratitude, and relationships with subjective well-being. J Soc Behav Pers 2003;31(5):431-51. https://doi.org/10.2224/sbp.2003.31.5.431

20. Toussaint L, Friedman P. Forgiveness, gratitude, and well-being: The mediating role of affect and beliefs. J Happiness Stud. 2009;10(6):635. https://doi.org/10.1007/s10902-008-9111-8

$\diamond \diamond \diamond \diamond \diamond \diamond \diamond$

http://www.ejgm.co.uk 